DOI 10.20396/temáticas.v1i1/2.11213

\title{
PARTICULARIDADE E UNIVERSALIDADE EM LUKÁCS E EISENSTEIN
}

Célia Aparecida Ferreira Tolentino

\section{INTRODUÇÃo}

Para que haja justeza num confrontamento entre Lukács e Eisenstein, devemos observar, antes de mais nada, que, ao usar os trabalhos teóricos de ambos, estaremos não utilizando do cineasta os seus discursos mais acabados, isto é, sua obra cinematográfica.

O que nos parecia, de início, a comparação entre duas obras muito díspares - uma do filósofo-crítico e a outra do artista - acabou por revelar vários pontos de convergência. Isto é, convergência de princípios teóricos. O materialismo dialético e histórico estão na base interlocutiva de ambos, o que faz interessante essa pequena discussão.

É importante ressaltar, antes de iniciarmos nossa análise, que Lukács nunca escreveu sistematicamente sobre cinema, tendo dedicado a maior parte de sua crítica da arte à literatura. Sobre o cinema se tem um texto seu de 1913 declarando-o uma arte capaz de promover uma fantástica recriação da realidade através de montagem de imagens fragmentadas que, entretanto, ao contrário do teatro, abole o princípio de realidade e da objetividade, implicando em uma perda total do significado das coisas. Para Brissac Peixoto,

Temáticas, Campinas, 1(1/2):127-152, jul./dez. 1993. 
de cujo texto extraio estas notas, a postura "radicalmente antimodernista" de Lukács já se evidenciava neste período com esta crítica ao movimento de montagem. ${ }^{1}$

A esse dado se complementa o fato do teórico húngaro nunca se haver entendido muito bem com as vanguardas da arte moderna, pois as achava incapazes de totalizar e dar conta das contradiçōes do real por uma preocupação formalista. Aos próprios escritores soviéticos do primeiro período que diziam preferir as inovações estilísticas de Joyce à Gorki, Lukács atribui "resíduos não superados das tradições burguesas decadentes". É interessante que, para dar conta das contradições do mundo burguês, Lukács eleja o realismo como a verdadeira arte literária e defenda o "realismo socialista" como a literatura soviética.

Eisenstein, por sua vez, traz em suas obras as influências das vanguardas artísticas dos anos 20 e sobretudo do movimento construtivista, a variante soviética (inclusive no sentido que se queria uma arte bolchevique) do cubismo e futurismo, condenado já em 1922 em favor do realismo. ${ }^{2}$ Tanto para os construtivistas como para Eisenstein, a arte do país dos soviets deveria ser inovadora como a própria proposta de uma nova sociedade. Os dirigentes do Proletkult, no entanto, discordavam destas vanguardas no que entendiam por arte inovadora e proletária. Mais tarde o próprio Lukács iria condenar o "excesso de realismo" da literatura oficial soviética, cuja falta de estrutura dramática a teria transformado em um apanhado de monografias e relatórios de fábricas e oficinas em lugar do que se queria romance, contos ou novelas.

Por fim, vale lembrar que tanto Eisenstein quanto Lukács sofreram repreensões do Partido Comunista por posiçōes não condizentes com a linha oficial. Ao que consta, nos escritos de ambos, a interlocução com os questionamentos oficiais estão presentes. Isso é mar-

${ }^{1}$ PEIXOTO, N. Brissac, $A$ sedução da barbárie, p. 36.

${ }^{2} \mathrm{NASH}, \mathrm{J}$. M., O cubismo, o futurismo e o construtivismo.

Temáticas, Campinas, 1(1/2):127-152, jul./dez. 1993. 
cante nos textos de Eisenstein que, em sua maioria, foram escritos em direção a justificar sua proposta cinematográfica.

$\mathrm{Na}$ primeira parte deste trabalho examinamos o conceito de particularidade em Lukács e o campo de construção deste conceito, a relação particular/universal na obra de arte. A segunda parte é dedicada a observar essa relação no campo da montagem cinematográfica através dos escritos de Eisenstein. A terceira e última parte propõe uma análise a partir da definição lukacsiana da categoria da particularidade na arte e um confronto com a posição do cineasta sobre o particular e universal na montagem dialética.

\section{LUKÁCS}

\section{Particularidade: Categoria Central da estética}

Nos fundamentos epistemológicos da construção da categoria de particularidade na estética de Lukács, a relação sujeito/objeto constitui um dos importantes eixos dessa démarche. Como pensador materialista, afirma, em nome da ruptura com a filosofia idealista, o primado da realidade objetiva no que chama de formas de apreensão do mundo, da ciência à arte, passando pelo conhecimento do cotidiano. Nesse processo de apreensão, tanto o conhecimento cotidiano quanto a ciência e a arte têm sua origem na experiência, no particular, de onde os dois últimos, no entanto, buscam um princípio geral.

As distinções específicas em relação aos três tipos de conhecimento estão, para Lukács, no ponto onde essa apreensão se fixa e recebe forma. $\mathrm{O}$ conhecimento ligado à prática cotidiana se fixa em qualquer ponto, a depender de suas tarefas concretas e práticas. $\mathrm{O}$ conhecimento científico, de acordo com suas finalidades se encaminha para o universal ou para o singular. $E$ a arte recebe forma $e$ fixa-se no particular.

Temáticas, Campinas, 1(1/2):127-152, jul./dez. 1993. 
Estes três campos da atividade humana, entretanto, refletem a mesina realidade objetiva que "é a mesma não só como conteúdo mas também em suas formas e categorias". ${ }^{3}$ Isto que aqui se chama de reflexo, é preciso afirmar, não se trata de um espelhamento da realidade, mas de uma forma específica de interposição, mediação entre o homem e a natureza, cada vez mais aprimorada. Lukács afirma que as transformaçōes histórico-sociais fizeram com que se aperfeiçoassem os orgãos receptivos, desdes os utilizados nas ciências naturais até os órgãos receptivos humanos, que se tornaram mais aprimorados em função das exigências cada vez mais diversificadas no trabalho e pelo fecundo intercâmbio e relações recíprocas com a ciência e a arte.

Ao pensar a arte como reflexo, Lukács observa que esta constitui um tipo especial de reflexo. A primeira característica que distingue a arte da ciência é que esta é antropomórfica. O conhecimento científico situa-se no âmbito da universalidade e ao intentar reduzir ao máximo a influência dos aspectos humanos, sociais, na apreensão dos fenômenos, tenderia à máxima desantropomorfisação. $\mathrm{O}$ reflexo estético, ao contrário, procede do mundo do homem e está destinado para este. No antropomorfismo da arte estão contidas todas as típicas relações da vida humana, questões e problemas socialmente condicionados, colocados pelo desenvolvimento das forças produtivas e modificadas pelas transformações das relações de produção. Assim a arte é fundamentalmente histórica tanto quanto sua essência. Para Lukács, e isso é fundamental para a categoria da particularidade, não existe uma essência "supra temporal" imanente à arte.

Pode-se dizer, fundamentando-se nesta definição, que a arte cria um retrato sensível de cada época ou sociedade. A arte em Lukács é datada, embora transcenda o gênero humano porque pode perdurar, ao contrário da ciência, que pode ser invalidada ou superada. Aponta Parkinson em sua discussão sobre a estética de Lukács:

\footnotetext{
${ }^{3} \mathrm{LUKÁCS}, \mathrm{G}$. Introdução a uma estética marxista, p. 160.
}

Temáticas, Campinas, 1(1/2):127-152, jul./dez. 1993. 
“... obra de arte não pode ser comparada à teoria científica. A ciência, segundo Lukács, se propõe a refletir o infinito - o que seguramente quer dizer que o objetivo último da ciência é a compreensão do universo -, porém a essência de tal reflexão é que só se aproxima de seu objeto, resultando que pode ser superada por teorias superiores". ${ }^{4}$ A obra de arte, completa e contida em si mesma, não é superada no sentido de ser substituida por obras posteriores. Observa Parkinson: "A física newtoniana supera e substitui a física cartesiana e essa não é a relação entre Mozart e Bach" ${ }^{5}$

$\mathrm{O}$ que é que define a obra de arte completa e contida em si mesma? Segundo a leitura de Parkinson, para Lukács é o "aqui e agora" da obra de arte, fundada na condição histórica de sua origem, refletindo uma realidade determinada que a faz ingovernável pela categoria da universalidade. Ressalva à qual, no entanto, este "aqui e agora" imanente confere a condição de porta voz de uma fase sócio-histórica do desenvolvimento da humanidade, impedindo que se atribua à arte uma pura individualidade, uma vez que contém elementos de generalidade. Assim, a arte não reflete meros indivíduos, vistos como entidades isoladas, tampouco leis universais. Sobre a arte convergem tanto elementos universais como individuais, o que lhe imputa a necessidade de uma categoria especial. Essa é uma das chaves para o que Lukács chama de particularidade da obra de arte.

Ainda segundo Parkinson, outro aspecto que complementa a definição de arte completa e contida em si mesma, é a distinção entre totalidade intensiva e totalidade extensiva utilizada por Lukács. Esta última, a totalidade extensiva é a que evoca a ciência. A arte evoca uma totalidade intensiva no sentido de que é um reflexo do

${ }^{4}$ PARKINSON, G.H.R. "Lukács, sobre la categoria central de la estética", in PARKINSON, G.H.R., (org), Lukács: el hombre, su obra $e$ su ideas, p. 145 (as citações foram por mim traduzidas livremente do espanhol).

${ }^{5}$ Idem, ibidem.

Temáticas, Campinas, 1(1/2):127-152, jul./dez. 1993. 
mundo do homem, do ponto de vista do homem e para o próprio homem.

Em suma, a obra de arte é antropomórfica e carreia para si elementos tanto universais como individuais. Essa conjunção provoca uma outra unidade que Lukács chama de comunidade de conteúdo e forma para onde convergem os termos singularidade, particularidade e universalidade. Vale dizer já aqui que Lukács pensa conteúdo e forma como coisas inseparáveis, muito embora seus escritos demonstrem o primado do primeiro sobre o segundo.

\section{Particularidade, Campo de Mediações}

A particularidade está, portanto, para Lukács fundamentalmente vinculada ao caráter gnosiológico da obra de arte, naquilo que o teórico vê como apreensão do real sob a especificidade de conteúdo e forma. Lembremos que, ao falar das três formas de conhecimento - o pensamento cotidiano, o pensamento científico e a arte - o pensador húngaro afirma que cada uma dessas formas se fixa em um determinado ponto, isto é, em direção ao singular ou universal, a depender de suas finalidades ou tarefas concretas e práticas.

Assim "enquanto no conhecimento teórico este movimento de dupla direção vai de um extremo ao outro, tendo o termo intermediário, a particularidade, uma função mediadora em ambos os casos, no reflexo estético o termo intermediário torna-se literalmente o ponto do meio, o ponto de recolhimento para o qual os movimentos convergem. Neste caso, portanto, existe um movimento da particularidade à universalidade (e vice-versa) e, bem como da particularidade à singularidade (e ainda vice-versa) e, em ambos os casos, o movimento para a particularidade é conclusivo". ${ }^{6}$ Esse ponto, como aponta Parkinson, poder-se-ia entender como um espaço para o movimento, não como um ponto médio entre dois pontos, mas um

${ }^{6}$ LUKÁCS, G., op. cit., p. 161.

Temáticas, Campinas, 1(1/2):127-152, jul./dez. 1993. 
campo de mediações entre o universal e o singular. Tais mediações, complementa Parkinson, são reais e não se trata de mero produto da consciência. São mediaçōes objetivas onde se coloca em grande medida a conexão dos objetos do mundo exterior.

O reflexo estético, ao descobrir e reproduzir "a totalidade da realidade explicitada em sua riqueza de conteúdos e formas", e ao ser realizado sob várias mediações e um processo subjetivo, provoca "modificações qualitativas na imagem reflexa do mundo". ${ }^{7} \mathrm{E}$, como forma específica de representação de uma realidade historicamente dada, supera os extremos, o universal e o individual, tornando-os síntese na particularidade. Vale dizer, o conhecimento estético se faz a partir de um dado conhecimento subjetivo, entretanto, traz em seu reflexo, aspectos da realidade objetiva (à medida em que faz uso de leis universais) e torna-se uma forma peculiar, especial de conhecimento para a humanidade, auto-conhecimento.

Lukács propõe que, como as outras esferas do conhecimento, seria impossível uma história das artes se não fosse observada nestas transformações da vida e da arte, que com ela amplia, seus poderes de cognoscibilidade. Enquanto no conhecimento científico tais transformaçōes significam a superação de estágios do conhecimento, nas artes ocorre o contrário. Isto é, o conhecimento "verdadeiramente" artístico permanece mesmo quando seus elementos estruturais e formais já estão há muito superados. Isto porque a etapa que a sucede não se utiliza da sua forma precedente - embora se utilize das experiências por ela acumuladas. Diferentemente da ciência, a prática do conhecimento estético recomeça do início, produzindo a peculiaridade da sua não-superação. Para Lukács, esse dado abriria a brecha para a sua mistificação, num sentido irracionalista (Lukács atribui essa leitura ao que chama de "reação filosófica").

Assim define o "realmente artístico" permanecente: "toda obra de valor discute intensamente a totalidade dos grandes problemas

${ }^{7}$ Idem, ibidem, p. 154.

Temáticas, Campinas, 1(1/2):127-152, jul./dez. 1993. 
de sua época: tão somente nos periodos de decadência estas questões são evitadas, o que se manifesta, nas obras, em parte como carência de universalidade, em parte como enunciação nua de universalidade não superada artisticamente (falsas $e$ distorcidas como conteúdo)", 8 Duas questões a ressaltar. A primeira é que a arte de um dado momento histórico deve, segundo esses enunciados, empreender a "síntese das questões de sua época", cujo estilo, segundo esse pressuposto, é componente do conjunto desse retrato sensível e específico de múltiplas determinações de uma época. A segunda questão é que nesta citação do pensador húngaro, já encontramos o contorno do que virá a chamar de arte da decadência e não totalizadora. Sob essa definição, o autor sobrepuja um estilo em detrimento de outro, isto é, faz a defesa do realismo e critica as manifestaçōes modernistas da arte da primeira metade deste século (cubismo, futurismo, surrealismo, construtivismo, etc.).

\section{Realismo: O "Realmente Artístico"}

Como observa Parkinson, sendo a particularidade um espaço de movimento ao redor de um ponto central, o estilo, o tônus de uma obra dependeria do movimento ascendente ou descendente dentro dessa unidade, aproximando-se ora do universal, ora do individual. Esse analista cita o exemplo dado por Lukács à obra de Dickens que em alguma de suas novelas "caracteriza a 'classe superior' por meio de generalizações satíricas, enquanto a 'classe inferior' é caracterizada por meio de uma amorosa atenção aos pequenos detalhes da vida cotidiana". 9

Parkinson observa ainda que, para Lukács, aproxima-se da essência da arte aquele que retrata a organização do mundo dinamicamente, como um sistema de movimentos, um sistema de tensões

\footnotetext{
${ }^{8}$ Idem, ibidem, p. 163.

${ }^{9}$ PARKINSON, G.H.R., op. cit., p. 153.
}

Temáticas, Campinas, 1(1/2):127-152, jul./dez. 1993. 
e contrastes. Esses diversos movimentos se distanciam ou se aproximam mais do singular ou mais do universal. E são esses extremos e a distância ou aproximaçāo deles que produzem a pluralidade das artes em gêneros e estilos e segundo a estética de Lukács: “... o drama concebe seus personagens e situações de um modo mais universal que a épica; os traços individuais aparecem em uma forma muito menos detalhada. Em geral pois, o drama tende para a universalidade, e a épica para a individualidade (...) Assim Racine está mais próximo da universalidade que Shakeaspeare...${ }^{p 10}$ A novela moderna e o moderno teatro burguês também estariam mais próximos da individualidade.

Parkinson acrescenta ainda que, quando Lukács fala em termos da arte na acepção avaliativa da crítica de arte, está falando da obra de arte realista. Para o pensador, o realismo é a base artística de toda criação autêntica e só uma postura realista poderia desmascarar a aparência em função da essência do real refletido. Nos outros estilos literários faltaria uma hierarquia para ordenar o real.

Essa leitura lukacsiana já aparece em Narrar ou descrever de 1936, quando discute a narração de Tolstoi em contraposição à descrição de Zola, definindo que no estilo do primeiro encontram-se os elementos de uma apreensão do real em suas contradições. O narrador, entende, se integra aos motivos geradores da ação do drama, enquanto que a descrição que reduz o homem à mesma estatura (importância) das coisas não coloca em questão os "motivos geradores". Na ordem narrativa as coisas se articulam e destaca-se o processo, enquanto que na descrição há um nivelamento das coisas e, os resultados é que são acentuados. Declara, ainda, a supremacia do realismo como a obra narrativa e condena o naturalismo como obra descritiva, observando, ao final, que uma arte pode sustentar-se como estrutura interna em um dado período, porém só será insuperável se der conta da apreensão da síntese do "aqui e agora".

${ }^{10}$ Idem, ibidem, p. 154.

Temáticas, Campinas, 1(1/2):127-152, jul./dez. 1993. 
Assim sendo, o realismo pode realmente superar o universal e o singular na particularidade enquanto o naturalismo só dá conta do singular.

Parkinson observa que Lukács conecta o tipo à literatura realista e define que "algo chega a ser um tipo na medida em que todos os 'momentos' humana e socialmente especiais de uma época histórica se reúnem nele. Na descoberta de personagens típicos e situações típicas, as tendênciäs mais importantes do desenvolvimento social recebem adequada expressão artística”. E cita a análise de Lukács a respeito de Tolstoi: "Em Ana Karenina o destino da heroina é um destino muito individual e, sem dúvida é também típico, enquanto revela nos termos mais vigorosos as contradiçōes internas do moderno matrimônio burguês". ${ }^{11}$

Assim, a tipicidade passa a ser uma categoria da particularidade, onde se pode ver a realidade no seu ponto mais avançado, ou seja, individualidade empírica, concreta que, não obstante, traz em si elementos de universalidade. Os tipos também estão na ciência, esclarece Lukács, que trata de generalizá-los o mais possível para asssumí-los no universal e reduzí-los a um número mínimo. No caso da arte, ao contrário, se mantém a pluralidade de tipos sem que se suprima o individual. Isto significa que na base do reflexo artístico está a unidade do individual com sua generalização, isto é, está o particular.

Nessa linha de raciocínio, a arte moderna para Lukács será vista como a arte incapaz de totalizar, porque é a arte mergulhada no fragmento, reprodutora do conhecimento compartimentado tal como a ciência positivista. Essa arte da fragmentação não daria conta do tempo histórico - alguns analistas sugerem da luta de classes -, ficando reduzidas a um conjunto de dados sem organicidade. Nesse lugar está a arte moderna, que peca pelo culto à forma sendo que sua maior parte não ultrapassaria a imediata subjetividade. Vale dizer aqui que, embora Lukács tenha tratado em especial da literatura,

${ }^{11}$ Idem, ibidem, p. 155.

Temáticas, Campinas, 1(1/2):127-152, jul./dez. 1993. 
estende essa análise a outras formas artísticas como a música e a pintura.

No que se refere às formas "inovadoras", podemos dizer que duas questões se destacam em Lukács. A primeira é que para superar Hegel, onde o conteúdo e a forma se convertem um no outro, é preciso estabelecer a prioridade do conteúdo, sem negar entretanto, a relação recíproca de conversão de conteúdo e forma e viceversa. Ou seja, assim realizar-se-ia uma leitura materialista dialética e histórica. ${ }^{12}$ A segunda questão a observar é a de como Lukács trata a superação e substituição de determinadas formas artísticas: “... é original o artista que consegue captar em seu conteúdo, em sua justa direção e em suas justas proporções, o que surge de substancialmente novo em sua época, o artista que é capaz de elaborar uma forma organicamente adequada ao novo conteúdo e por ele gerada como forma nova". ${ }^{13}$

Ou seja, por princípio, Lukács admite que as transformações histórico sociais geram formas novas de reflexo e apreensão artística do real. Ressalta, porém, que se faz necessário que o artista tome uma posição perante a realidade reproduzida para garantir a verdadeira arte. E, acrescenta que, a universalidade e justeza do novo em sua real essência deve mesmo favorecer a variedade e originalidade da forma. A Mãe de Gorki é, para Lukács um exemplo do novo, de uma representação sensível de homens novos.

\section{Partidarismo na Arte}

Para Lukács, todo artista inevitavelmente assume uma posição diante da realidade reproduzida. Mesmo o poeta, ao falar da primavera ou do inverno, exibiria sua atitude perante as tendências e lutas de seu tempo.

${ }^{12}$ LUKÁCS, G., op. cit., p. 182.

${ }^{13}$ Idem, ibidem, op. cit., 207.

Temáticas, Campinas, 1(1/2):127-152, jul./dez. 1993. 
Sob esse preceito, uma obra que não der conta de posicionar o subjetivo particular do artista e sua relação com a raça humana, em seu momento historicamente dado, não será uma obra genuinamente artística. É o que atribui aos escritores que seguem o método descritivo, por exemplo. Para Lukács, esses escritores "registram sem combater os resultados 'acabados', as formas constituidas da realidade capitalista, fixando somente os efeitos mas não o caráter histórico conflitivo, a luta de forças opostas". ${ }^{14}$ Narrar ou descrever significa, como mostra o fechamento do texto: "participar ou observar?"

Dois exemplos de obra que reproduzem esse sentido da particularidade encontramos, segundo Lukács, em Balzac e Cervantes. E cita Marx, concordando com ele que: "Balzac não foi apenas o historiador de sua época, mas o criador profético de personagens ainda embrionários nos dias de Luis Felipe e que não desabrochariam completamente senão depois de sua morte, no governo de $\mathrm{Na}$ poleão III". ${ }^{15}$ Quanto a Cervantes, o seu Don Quixote expressaria a sua tomada de posição na luta entre o feudalismo moribundo e o mundo burguês nascente, através da pureza e comicidade do personagem.

E, para finalizar, é importante observar para o desenvolvimento de nossa discussão subseqüente, que, para Lukács, o grande problema das artes modernas estava justamente na incapacidade dos artistas transcenderem o subjetivo em direção ao particular - campo de forças organizador da relação singular/universal.

A arte é, na acepção lukacsiana, algo muito importante para o desenvolvimento sócio-histórico do homem, observa Parkinson, fundamentalmente porque apresenta, de uma forma concreta e emocionalmente evocadora, as leis histórico-sociais que governam os seres humanos.

${ }^{14}$ LUKÁCS, G., Narrar ou descrever, p. 88.

${ }^{15}$ Idem, ibidem, p. 231.

Temáticas, Campinas, 1(1/2):127-152, jul./dez. 1993. 


\section{EISENSTEIN}

\section{Organicidade da Obra de Arte}

Particular e universal nos escritos de Eisenstein recebem filiação em Engels e Lênin. Da Dialética da natureza de Engels toma a definiçāo de que "o organismo é uma unidade superior". E de Lênin: "o particular só existe na relação que leva ao geral. O geral só existe no particular, através do particular" ${ }^{16}{ }^{\mathrm{E}}$ no corpo desse referencial teórico que Eisenstein fala em obra de arte, embora esteja pensando primordialmente o cinema.

Como aponta Deleuze, o cinema, ao contrário das outras artes, é dotado de movimento próprio e não depende de um espírito que o execute ou reconstitua. ${ }^{17} \mathrm{O}$ cinema ultrapassa os limites da coreografia ou da palavra. Seus truques podem levar a imagem em seu desenvolvimento imediatamente ao cérebro. Assim, mostra Deleuze, os grandes pioneiros do cinema, entre eles Eisenstein, conscientes de tal peculiaridade, acreditavam que esta seria a arte do choque que despertaria no espectador o pensador, à medida que falasse tão diretamente ao "pensamento". Eisenstein pensava um cinema cujas partes e partículas, formadas pela montagem e movimento, desenvolvesse o processo mesmo do pensamento, realizando um "choque sobre o espírito", forçando-o a pensar o Todo.

Com isso, já supunha Eisenstein (e não só ele), que o cinema era a arte das massas e poderia realizar mais de uma espécie de movimento em direção ao pensamento coletivo. Para o cineasta, entretanto, importava realizar um cinema que desse conta do processo dialético da imagem-movimento, de forma a levar quem o visse a um estágio específico de "choque", onde o todo fosse visto em seu processo de conformação a partir de oposições mobilizadoras. Essa "intenção" de um processo dialético deveria estar desde a mais es-

${ }^{16}$ EISENSTEIN, A forma do filme, p. 144.

${ }^{17}$ DELEUZE, G., A imagem-movimento, p. 189.

Temáticas, Campinas, 1(1/2):127-152, jul./dez. 1993. 
pecífica "célula" de imagem até o corpo estrutural da obra como um todo.

Para Eisenstein, numa obra de arte orgânica todos os elementos são sustentáculos constitutivos em todos os níveis e aspectos que a compõem. O mesmo critério deve impregnar cada parte em especial, cada área chamada a participar do trabalho de composição. Essa integração parte-todo e vice-versa deve estar disposta dialeticamente.

A qualidade orgânica de uma obra, dada a perceber por ela mesma, deve aparecer como na lei dos fenômenos naturais, numa totalidade dotada de leis internas e de uma lei estrutural, sob a qual se encontram subordinadas todas as suas partes. Esse é o princípio da lei dos organismos da natureza. Essa é a definição de Eisenstein que propõe que sua obra dê conta, não só da aplicação desse princípio, mas da própria lei.

O cinema estaria colocado para o espectador como logos (conceito) materializado em luz, tom, movimento, ritmo, som etc. O todo, a estrutura da obra, que Eisenstein chama de conceito, é o tema ou assunto, resultante de partes constitutivas em movimento. As partes por sua vez, formam um todo em si que, embora distintos uns dos outros, mantêm estreita conexão temática com a estrutura principal, uma vez que dela contêm elementos.

A esse organismo soma-se a qualidade peculiaríssima do cinema de operar com um pathos próprio. Isto é, um filme pode mover sua composição de forma qualitativa e definir sua própria "emoção" interna, e com isso falar diretamente ao pathos do espectador. Deleuze observa que, ao propor o patético como correlato do orgânico, Eisenstein estaria pensando que enquanto um deveria corresponder ao "pensamento sensorial" o outro deveria falar à "inteligência emocional".

Temáticas, Campinas, 1(1/2):127-152, jul./dez. 1993. 
Essa concepção fica clara no exemplo de $O$ encouraçado Potemkin, filme cujo assunto é o sentimento de unidade revolucionária. $\mathrm{O}$ pathos quę move em direção ao tema se faz através da oposição geradora, um movimento iniciado na célula do navio (um grupo de marinheiros revoltados) que vai para todo o organismo do navio, do navio para a esquadra e da esquadra para a revolução. As oposiçōes estão colocadas em cada partícula da estrutura do filme dividido em cinco episódios (tirados da estrutura da tragédia clássica). 0 filme contém duas metades e entre elas uma ruptura que as diferencia. $\mathrm{Ou}$ seja, uma ruptura no ponto central que mobiliza a ação da segunda metade. O tema inicia-se no mar, vai para a cidade (em oposição física ao mar, mas a ele unida pelo sentimento de solidariedade) e volta ao mar para fechar o processo iniciado.

Oposiçōes como estas estão contidas em todas as sequências onde os movimentos dos personagens executam uma oposição ao seus próprios estados iniciais: quem está sentado se levanta, quem está silencioso, berra; o entorpecido, brilha; e assim por diante. De tal modo que o espectador se sinta compelido a participar no mesmo nível do pathos da obra. Para Eisenstein, uma obra com esses princípios de organicidade faz com que o tema e o assunto sejam assimilados mesmo num conjunto de espectadores onde tais questões não estejam na ordem do dia: "Isto pode quebrar a resistência até do espectador cuja sujeição de classe está em franca oposição à direção tomada pelo assunto e tema da obra ...." ${ }^{18}$

Alguns movimentos no conjunto de $O$ encouraçado Potemkin garantem o que Eisenstein chama de transição de "uma qualidade para uma nova qualidade" com relação ao pathos. Numa sequência da "Escadaria de Odessa" esse processo é construído através da montagem de um conjunto de oposiçōes:

1. O tempo aumenta / o ritmo (dos soldados) acelera

2. A massa precipita pela escadaria vertiginosamente/ uma

mãe sobe lenta e solenemente com o filho morto nos braços

${ }^{18}$ EISENSTEIN, op. cit., p. 144.

Temáticas, Campinas, 1(1/2):127-152, jul./dez. 1993. 
3. Um carrinho de bebê rola escada abaixo / o movimento dos soldados é rítmico

4. Fechamento com os leões de pedra que se levantam: o rítmico $\mathrm{x}$ o poético

Para Eisenstein, esse era o processo de montagem de uma obra tanto monística quanto dialética. Em um discurso justificativo para o poder central soviético, esclarece a respeito do processo de montagem, ao ser acusado de formalismo, já no início dos anos 30: "Para nós o microcosmo da montagem tinha de ser entendido como uma unidade que, devido a tensão interna das contradições, se divide para reunir numa unidade nova de um novo plano, qualitativamente superior, a imagem concebida de modo novo." 19

\section{Pars Pro Toto}

A discussão parte-todo na obra de Eisenstein não pode deixar de ser situada como ele a entendia, na linha da pesquisa do cinema como uma linguagem imagético-sensorial fundamentado na linguística, psicologia e antropologia. É preciso ressaltar, entretanto, que grande parte dessas discussões tinha como endereço a necessidade de não se deixar aproximar do idealismo hegeliano. $\mathrm{O}$ discurso político cinematográfico deveria ser uma mediação fundada em concretude, isto é, no reflexo da própria realidade.

Nos seus trabalhos de 32 e 35 , há uma preocupação constante com o que Eisenstein chama de "discurso interior" e sua sintaxe específica. O outro aspecto é o que denomina "pensamento primitivo", fundamentando-o na psicologia e antropologia para discutir a montagem visual como forma de representações que se aproximariam de determinados elementos "arcaicos", típicos de estágios primários de representação mental.

${ }^{19}$ Idem, ibidem.

Temáticas, Campinas, 1(1/2):127-152, jul./dez. 1993. 
A sintaxe do pensamento interior, observa Eisenstein, é distinta do discurso manifesto. $O$ pensamento interior não é dotado de construçōes lógicas, é dotado de estrutura específica. Para o cineasta, as leis que regem o discurso interior são as mesmas que regem as várias regras de construção de forma e composição da obra de arte. Assim, propõe, pode-se construir um cinema baseado em uma montagem intelectual, isto é, uma montagem que fale diretamente aos sistemas nervosos superiores do pensamento, com seu grau de movimento, atonalidade, ritmo etc. Esse é o princípio do cinema intelectual, que na sua forma mais avançada deve realizar uma síntese de ciência, arte e militância de classe. Para Eisenstein, ao falar na sintaxe do pensamento interior poder-se-ia dar um tratamento de classe aos fenômenos (aparência), imprimindo-lhe o ponto de vista da essência (processo).

Quanto aos elementos do folclore, míticos, das normas residuais de comportamento primitivo, elementos da tradição, Eisenstein entende que estes possuem os mesmos métodos e técnicas de representação das empregadas no discurso cinematográfico. Os signos específicos dessas formas representativas permitem, propõe Eisenstein, que se decodifique e se faça tão bem impressionar por alguns recursos da técnica artística. Um dos elementos muito difundidos é o pars pro toto, que produz grande efeito. Isso corresponde ao que nas comunidades primitivas se faz com relação a certos hábitos cotidianos. Um exemplo poderia ser o significado do dente de urso presenteado que deve conferir a quem o recebe a mesma força do animal. Isto é o pensamento pré lógico. Entretanto quando uma menina zangada rasga a foto do namorado infiel para vingar-se dele, ela está repetindo elementos desta estrutura arcaica de pensamento.

"O pince-nez do médico, no Potemkin, ficou gravado na memória dos que assistiram ao filme. O procedimento consistia na substituição do todo (o médico) por uma parte (o pince-nez), efeito que conseguia uma intensidade sensorial muito maior do que teria a reaparição do próprio médico.

Temáticas, Campinas, 1(1/2):127-152, jul./dez. 1993. 
Assim, este procedimento é o exemplo mais típico de uma forma de pensamento próprio ao arsenal de pensamento primitivo". ${ }^{20}$

Isso é uma figura comum na literatura observa, a sinédoque, que se divide em duas espécies:

- Apresentação da parte em lugar do todo (que apresenta uma série de subdivisões)

- O todo em lugar da parte.

De qualquer forma, ambas as espécies estão sujeitas a uma condição básica: a da identidade da parte e do todo e da possibilidade de equivalência ao se substituírem.

O segundo aspecto do pars pro toto vem do elemento inverso também tomado dos velhos costumes primitivos. Eisenstein exemplifica utilizando o costume polinésio de abrir portas e porteiras, retirar tangas, cocares e colares de todos os membros da aldeia, no momento que uma mulher polinésia vai dar a luz. De forma que o todo se componha para "abrir os caminhos" da nova criança para sua chegada ao mundo. Desse modo, todos os elementos da obra devem estar em consonância com o elemento principal: a luz, o ritmo, a música, o tom devem compor-se para o tema principal.

Para Eisenstein, essa é a composição dialética da obra cinematográfica, constituída sobre essa "duo unidade": uma construção que leve o conceito (tema ou assunto) rumo aos níveis mais elevados da consciência, e uma estruturação da forma que fale às camadas mais profundas do pensamento sensorial. Estes polos opostos devem criar a tensão da "unidade de forma e conteúdo, que caracteriza as verdadeiras obras de arte. Sem esta, não existe obra de arte autêntica". ${ }^{21}$

Pode-se concluir que, para Eisenstein, o cinema operaria através da construção de um conceito (tema) e uma linguagem para decifrá-lo, onde todos os elementos se imbricassem e se complemen-

${ }^{20}$ EISENSTEIN, S. "Novos problemas da forma cinematográfica", p. 226.

${ }^{21}$ Idem, ibidem, p. 238.

Temáticas, Campinas, 1(1/2):127-152, jul./dez. 1993. 
tassem mantendo uma tensão interna. Observa o cineasta que os princípios de oposição interna comporiam a linguagem dialética do verdadeiro cinema revolucionário. Outras formas de composição existem, afirma, e Griffith é um exemplo de outra espécie de discurso, coerente com sua leitura de mundo, isto é, a leitura de um liberal que deriva na montagem paralela, típica criação do cinema americano.

\section{Reflexo e Partidarismo}

"A questão da montagem se baseia numa estrutura definida de reflexo e num sistema de pensamento definido, deriva e derivou, apenas da consciência coletiva, que é um reflexo de um novo (socialista) estágio ${ }^{22}$ da sociedade humana e um resultado da educação ideológica e filosófica do pensamento, inseparavelmente vinculada à estrutura social dessa sociedade."

Eisenstein estaria convencido de que o "país dos soviets" deveria inaugurar um cinema tão novo como a sociedade que representava. A velha forma realista advinda das expressões artísticas do século XIX nada teriam a ver com a arte soviética, muito menos com o cinema, ainda por construir.

Esse discurso era a contraposição do cineasta às críticas a ele endereçadas - sobretudo na era Stálin - no sentido de estar fazendo um cinema pouco "quente" e "vivo" em função do cinema intelectual.

$\mathrm{O}$ cinema intelectual baseado numa montagem dialética seria, segundo o cineasta, uma forma de realizar o conteúdo histórico socialista, cujas possibilidades se mostravam incomensuráveis com as inovações técnicas da nova arte. O. uso do som, por exemplo, viria ainda mais reforçar tais premissas.

${ }^{22}$ EISENSTEIN, S. A forma do filme, p. 205.

Temáticas, Campinas, 1(1/2):127-152, jul./dez. 1993. 
O próprio tratamento conferido ao pathos de um filme, observa Eisenstein, impele o autor a se posicionar perante o conteúdo e leva o espectador a se relacionar do mesmo modo. Portanto, uma estrutura patética levaria o espectador, a partir do seu movimento, a reviver os momentos culminantes de substanciação que formam a base de todo pensamento dialético.

De modo que, a posição do cinema soviético na construção do pathos não poderia se igualar à montagem paralela de Griffith, por exemplo, cuja obra era para Eisenstein, sem dúvida grandiosa e descobridora. Mas, era natural, propunha, que o espírito e o conteúdo do cinema soviético fosse além dos ideais de Griffith e de seus reflexos nas imagens artísticas.

$\mathrm{Na}$ visão social liberal do cineasta americano não pairaria nada além de um humanismo levemente sentimental, digno dos velhos cavalheiros e doces madames da Inglaterra vitoriana, do modo como Dickens adorava retratá-los. Havia, no cinema de Griffith, apenas uma moral piedosa sobre o velho conflito pobres/ricos.

A estrutura de montagem é inseparável do conteúdo do pensamento como um todo, reafirma Eisenstein:

"A estrutura de Griffith é a da sociedade burguesa: composta em uma complicada corrida em duas linhas paralelas onde se encontra o contraste social possuidores/despossuidos na forma dicotómica dualista. Por isso Griffith é o mestre da montagem paralela fundamentada no tempo para a qual se contrapôs a montagem fundamentada no ritmo, do cinema soviético. Isso impressionou os americanos. Mas, para converter o cinema em ritmo é preciso unidade orgânica, antes de tudo. ${ }^{\mathbf{2} 3}$

A sua conclusão do processo inaugurado pelo cinema americano é fundamental para embasar sua tese da arte como reflexo do real: "a montagem paralela de Griffith parece ser uma cópia de sua visão dualista de mundo que corre através de duas linhas, rico e pobre em

${ }^{23}$ Idem, ibidem, p. 198.

Temáticas, Campinas, 1(1/2):127-152, jul./dez. 1993. 
direção a uma 'reconciliação' hipotética onde as paralelas se cruzariam, isto é, no infinito, tão acessivel, quanto a 'reconciliação' ". ${ }^{24}$

$\mathrm{E}$ entendendo que o cinema soviético devesse expressar a concepção dialética da história que alimentava o cinema revolucionário, afirma Eisenstein: "para nós a montagem se tornou um meio de adquirir uma unidade de ordem superior - um meio, através da imagem de montagem, de adquirir uma personificação orgânica de uma concepção ideológica singular, abarcando todos os elementos, partes, detalhes da obra cinematográfica. ... E de acordo com este principio de nossa montagem, unidade-e-diversidade soam ambas como principio" ${ }^{25}$

\section{A Categoria da Particularidade e a Proposta ARTística DE EISENSTEIN}

\section{Arte como Reflexo do Real}

A arte como reflexo da realidade e como forma de apreensão do mundo é um dos pontos convergentes em Eisenstein e Lukács.

Para o teórico húngaro, a arte se mantém peculiar em relação à ciência na medida em que carreia para si o singular e o universal.

Eisenstein observa que o seu método de desenvolvimento de uma obra cinematográfica parte de um conceito (tema, assunto) - como o próprio cineasta sugere, quase que hegelianamente - e caminha em direção à conversão desse conceito em processo. Isto é, em uma estrutura de imagens e movimentos que possa representá-lo em constituição e que fale diretamente ao raciocínio do espectador.

\footnotetext{
${ }^{24}$ Idem, ibidem, p. 211.

${ }^{25}$ Idem, ibidem.
}

Temáticas, Campinas, 1(1/2):127-152, jul./dez. 1993. 
Estaria Eisenstein cometendo o pecado da aproximação.excessiva da universalidade ao tomar como princípio o conceito como caminho para apreensão do real? O cineasta resolve esta questão quando observa que, na sua intenção de uma obra fundamentada nos princípios da dialética, o que entende por conceito mantém inteira relação orgânica com a realidade da qual fala. Ou seja, trata-se do real covertido em síntese. É o real particularizado historicamente, cujo conceito é a síntese de um conjunto de condições específicas, sem o risco da reificação.

As obras de Eisenstein podem responder com exemplos mais claros. Tomando-se $O$ encouraçado Potemkin como exemplo, a sínteseconceito da solidaridade revolucionária recebe na estrutura um tratamento dialético. Isto é, o conceito - a solidariedade revolucionária - é resultado de um processo histórico de lutas de classes, de contradições sociais. Tais contradições deveriam compor o filme para suscitar no espectador o processo (via raciocínio e pathos) da construção da síntese.

Essa é uma discussão sobre a estrutura interna da obra. Se colocada no contexto, a obra $O$ encouraçado Potemkin traz em si, desde o tema até a construção da obra como um todo, a síntese das mediações objetivas de uma época, tratando questões universais (a luta de classes) a partir de uma situação singular (o encouraçado revoltado) e de uma leitura sensível e sem dúvida, crítica, como propunha Lukács. Onde se localizaria o "personagem típico" carreador dos momentos "humanamente essenciais"?

A essa questão Eisenstein responde que o típico no "país dos soviets" é a massa organizada. Mesmo quando o culto à personalidade da era Stálin lhe exige um herói, sua compreensão é de que de um tamanho igual a imagem do herói é a imagem do homem do povo. Síntese que poderemos atribuir a Alexandre Nevski, o herói do filme homônimo que conta com a massa de camponeses para a vitória da Rússia contra a invasão teutônica (se passa no século XII) - que aparecem mais destacados que o exército do príncipe, através de um

Temáticas, Campinas, 1(1/2):127-152, jul./dez. 1993. 
grupo de indivíduos típicos representantes da coragem, sagacidade e patriotismo não vistos nos homens ricos da cidade.

Para Eisenstein, os determinantes objetivos que transformam os indivíduos subjetivamente estariam sempre claros em suas obras. Acreditava, no entanto, $e$ isso lhe rendia problemas com os dirigentes soviéticos, que não deveria utilizar uma estética do século XIX (o realismo) para falar de um conteúdo novo.

Está claro, pelo menos em discurso, que Eisenstein faz convergir para sua obra os elementos fundamentais propostos por Lukács para a realização de uma verdadeira arte. Isto é, trata-se de uma obra politicamente posicionada, que se propõe a captar o real em seu movimento, tratando de explicitar as condições determinantes deste mesmo real que observa a partir de situaçōes singulares.

Entretanto, o considerado cinema da narrativa, no sentido lukacsiano, é típicamente o neo-realista italiano. O retrato de um contexto histórico-social se dá a partir de um personagem típico, cujas condições objetivas determinam sua visão de mundo, seu estar no mundo e o desenvolvimento de suas açōes. Para um exemplo mais concreto de um filme realista poderíamos citar Vidas secas, de Nelson Pereira dos Santos, baseado no romance realista de Graciliano Ramos. Fabiano, o personagem central é o típico retirante nordestino, cujo destino particular é marcado pela trajetoria típica de milhares de retirantes nordestinos.

O cinema hollywoodiano, da câmera invisível, cujo olhar nada hierarquiza, podemos chamar de naturalista e descritivo no sentido proposto por Lukács.

Eisenstein narra ou descreve? Segundo o próprio cineasta, a estrutura de seus filmes está mais próxima da construção de um poema. Assim reagiu ao ser acusado de formalista por Maximo Górki.

Mas a obra de Eisenstein dá conta daquilo que exige Lukács, antropomorfizar as tendências e lutas verdadeiramente grandes do seu tempo. Sobretudo dando-lhes uma forma nova para o que chama

Temáticas, Campinas, 1(1/2):127-152, jul./dez. 1993. 
de conteúdo novo - reflexo do novíssimo país dos soviets. Não cabia, a seu modo de ver, refazer a apreensão esteticamente superada dessa realidade nova.

Entretanto, a essência que determina a seleção e organização dos detalhes da obra de arte, como propōe Lukács, é em Eisenstein a leitura dialética de mundo. A ele não se poderia atribuir o dogmatismo subjetivista e esquemático, resultando a "originalidade rebuscada e arbitrária" incapaz de totalizar, enderaçada a Beckett e Kafka.

Por fim vale notar que Eisenstein se fundamenta em Marx, Engels, Lênin, Hegel, assim como Lukács, mas ao cineasta não se pode atribuir o esquematismo do realismo socialista, criticado por aquele teórico que observa que as obras literárias oficiais soviéticas mais pareciam relatórios e monografias de fábricas e usinas por absoluta falta de tensão dramática e absoluta previsibilidade. Nestas obras, sobretudo do período stalinista, não se dava espaço para "contradições" e os personagens eram sempre monolíticos, segundo observa Lukács.

Talvez devêssemos concluir esse trabalho com uma indagação: teria Lukács utilizado, de fato, seus princípios teóricos para criticar a vanguarda?

Para nossa análise, a obra de Eisenstein supera o universal e o singular no conjunto de suas obras (-primas), realmente dotadas de historicidade e originalidade dignas do momento histórico que as gerou. Esse é o particular originário da sua experiência, cujo princípio estava na superação da sociedade de classes. Essa era a tese, e com ela concordava Lukács.

Temáticas, Campinas, 1(1/2):127-152, jul./dez. 1993. 


\section{BIBLIOGRAFIA}

BERMAN, M., Tudo que é sólido desmancha no ar, Companhia das Letras, São Paulo, 1987.

COSTA, H.A., Memória do cinema, Afrontamento, Porto, s/d.

DELEUZE, G., A imagem-movimento, Brasiliense, São Paulo, 1990

EISENSTEIN, S., A forma do filme, Zahar, Rio de Janeiro, 1990.

- . "Novos problemas da forma cinematográfica", in Xavier, I. (org.), A experiência do cinema, Graal, Rio de Janeiro, 2ạ edição, 1990.

- . "O encouraçado Potemkin", in Cinetexto, Global, São Paulo, 1982.

- O sentido do filme, Zahar, Rio de Janeiro, 1990.

GOLDMAN, L., "A Reificação" in Dialética e Cultura, Paz e Terra, Rio de Janeiro, 1967.

LUKÁCS, G., Introdução a uma estética marxista, Civilização Brasileira, Rio de Janeiro, 1978.

- História e consciência de classe, Publicações Escorpião, Lisboa, 1974.

- . "Narrar ou descrever" in Ensaios sobre Literatura, Civilização Brasileira, Rio de Janeiro, 1968.

METZ, C., Linguagem e cinema, Perspectiva, São Paulo, 1971.

NASH, J.M. O cubismo, o futurismo e o construtivismo, Editorial Labor do Brasil, Barcelona, 1976.

NETTO, J.P., "Lukács: guerreiro sem repouso", in Coleção Encanto Radical, v. 28, Brasiliense, São Paulo, 1983.

PARKINSON, G.H.R., "Lukács, sobre la categoria central de la estética" in PARKINSON, G.H.R. (org), Lukács: el hombre, su obra e sus ideas, Ed. Grijalbo, Madrid, 1973.

Temáticas, Campinas, 1(1/2):127-152, jul./dez. 1993. 
PASCAL, R., "Georg Lukács: el concepto de totalidad", in PARKINSON, G.H.R., (org) Lukács: el hombre, su obra e sus ideas, Grijalbo, Madrid, 1973.

PEIXOTO, N. Brissac, A sedução da barbárie, Brasiliense, São Paulo, 1982.

XAVIER, I., Sertão Mar, Brasiliense, São Paulo, 1983.

Temáticas, Campinas, 1(1/2):127-152, jul./dez. 1993. 